\title{
Erythropoietin and iron for anemia in HIV-infected patients undergoing maintenance hemodialysis in China: a cross-sectional study
}

\author{
Lei Peng ${ }^{1,2 \dagger}$, Yanan $\mathrm{He}^{3 \dagger}$, Jiong Zhang ${ }^{1}$, Daqing Hong ${ }^{1 *}$ and Guisen $\mathrm{Li}^{1}$
}

\begin{abstract}
Background: Anemia is a common complication of chronic kidney disease (CKD) and HIV infection. The number of people living with HIV on hemodialysis (HD) is increasing. However, there is no data about anemia and related therapies in this kind of patients in China. We aim to assess the difference in hemoglobin (Hgb) and treatments like erythropoietin and iron between HIV-HD patients and HD patients in Chengdu, China.
\end{abstract}

Methods: This cross-sectional study was conducted with data collection from January 2020 to June 2020. Thirty-four HIV-infected HD patients and thirty-five non-HIV-infected HD patients were included. Age, gender, dialysis vintage, single-pool (sp) Kt/N, Hgb, the dose of erythropoietin, ferritin, use of iron preparations, and serum albumin were collected in all patients. Time since HIV diagnosis, counts of CD4 + T cells, HIV RNA, and antiretroviral therapy for HIV infection were collected in HIV-infected patients. T-test, Mann-Whitney $U$ test, and chi-square statistics were applied in SPSS.

Results: The Hgb of HIV-HD and HD groups were 105.70 (95.93-112.08) g/L and 112.00 (93.00-126.00) g/L respectively $(P=0.064)$. There was a statistically significant higher erythropoietin dosage used in the HIV-HD population $(222.55 \pm 115.47 \mathrm{U} / \mathrm{kg} /$ week) compared to the HIV-negative HD group $(161.86 \pm 110.31 \mathrm{U} / \mathrm{kg} /$ week) $(P=0.029) .16 / 34$ (47.06\%) HIV-HD patients and 5/35 (14.29\%) HD patients were treated with iron preparations $(P=0.003)$. The ferritin levels were 316.50 (117.38-589.75) ng/ml and 272.70 (205.00-434.00) ng/ml in HIV-HD and HD groups respectively.

Conclusions: A higher erythropoietin dosage and a higher probability of iron preparations may be required to maintain Hgb in HIV-HD patients compared with HD patients.

Keywords: Erythropoietin, Iron, Anemia, HIV, Hemodialysis

*Correspondence: hongdaqing11@126.com

†Lei Peng and Yanan He were co-first authors, they contributed equally to this work

1 Department of Nephrology, Sichuan Provincial People's Hospital, University of Electronic Science and Technology of China,

Chengdu 611731, China

Full list of author information is available at the end of the article

\section{Background}

The incidences of acquired immunodeficiency syndrome (AIDS) associated events and death among people living with HIV (PLWH) have reduced over the last two decades due to increasing HIV testing and antiretroviral therapy (ART) [1]. However, non-AIDS-defining diseases (NADs), such as cardiovascular disease and kidney disease, were more prevalent in PLWH than HIV-uninfected individuals, which have become the main causes 
of death among PLWH in the era of modern ART [2, 3]. In a cohort of PLWH in China during 2010-2019, the incidence of advanced kidney disease was 270 per 100,000 person-years of follow-up after initiation of ART, which has become the second common NADs [4]. ART, infections (including HIV, BK virus, et.al), HIVassociated nephropathy, HIV-immune complex disease, and HIV-thrombotic thrombocytopenic purpura / hemolytic uremic syndrome may result in renal lesions and may eventually progress to end-stage renal disease (ESRD) which need dialysis treatment [5-7]. The number of PLWH on dialysis is increasing and survival rates of these patients are similar to those in the HIV-negative dialysis population [5, 8]. However, in another clinical trial, the one-year survival of HIV-positive hemodialysis (HD) patients seems to be lower compared to their HIV-negative counterparts [9] and the hemoglobin ( $\mathrm{Hgb})$ of HIV-positive dialysis patients was lower than that of HIV-negative people [10].

Anemia is a common complication of chronic kidney disease (CKD) and HIV infection [11, 12] and is associated with an increased risk of cardiovascular events, and all-cause mortality [13]. Thus, correction of anemia is an important task in the management of CKD complications. There are many reasons for anemia in HIV-HD patients. HIV infection may cause defective myelopoiesis/erythropoiesis, as well as the accumulation of myeloid/erythroid precursors, and may increase levels of inflammatory cytokines, affecting dynamics and functions or inducing Fas-mediated apoptosis of hematopoietic stem/progenitor cells, which consist of progenitors for all blood cell lineages including erythroid progenitors [14]. Opportunistic infections, antiretroviral drugs, other drugs administered to treat infection, and malignancies in HIV-positive patients could exacerbate the severity of anemia [15]. Relative erythropoietin deficiency, shortened erythrocyte lifespan, increased blood loss, chronic inflammation, iron deficiency, copper deficiency, vitamin B12 deficiency, folate deficiency, and aluminum overload result in anemia in HD patients [12]. Therefore, anemia in HIV-HD patients is theoretically more difficult to control. In fact, the Hgb of HIV-positive dialysis patients was lower than that of HIV-negative patients in a previous clinical trial [10]. Therapy with erythropoiesis-stimulating agents (ESAs) is an appropriate treatment for anemia in HIV-HD patients. Iron may be important in the activation of HIV-1 and high iron stores may also adversely influence the outcome of HIV-infected patients. Closely monitoring HIV disease progression in patients receiving intravenous iron by measuring plasma viral loads and $\mathrm{CD} 4+\mathrm{T}$ cell counts is essential. Blood transfusions in HIV-infected patients with CKD should be avoided as some studies have shown increased activation of HIV-1 after transfusion, which could potentially accelerate HIV disease.[15]. The response to erythropoietin in HIV-infected patients appears to be similar to HIVnegative patients in a small study of HIV-HD patients [16]. However, in another study, there was a statistically significant higher erythropoietin dosage used in the HIV-HD patients as compared to the control group [17]. Up to now, there is no research on anemia and its treatment in HD patients with HIV infection in China. This study focused on anemia and its therapeutic strategy in southwestern areas of China and further explored the current status of anemia in HIV-HD patients and the optimization of treatment options.

\section{Materials and methods}

\section{Patients and data collection}

We conducted this cross-sectional study with data collection from January 2020 to June 2020. Thirty-four HIV-infected adult patients from the Public Health Clinical Center of Chengdu were enrolled. A group of HIVnegative patients were then selected as control in a 1:1 ratio from Sichuan Provincial People's Hospital in China. Available influencing factors on $\mathrm{Hgb}$ including age, gender, dialysis vintage, single-pool (sp) Kt/V, serum albumin, frequency of hospitalizations, frequency of infection and medications were compared and considered when selecting the control group. Thirty-five non-HIVinfected patients were selected from 394 patients in the study. All participating patients aged 18 to 75 years were on maintenance HD therapy $\geq 3$ months and received HD three times a week. The diagnosis of HIV/AIDS was based on the Diagnostic Criteria for HIV/AIDS (WS 293-2008) [18]. The patients who had hematologic diseases causing anemia (including aplastic anemia, hemolytic anemia, bleeding, and so on), severe active infection, and tumors were excluded. Erythropoietin which enrolled patients used were all of domestic origin.

Age, gender, dialysis vintage, single-pool (sp) Kt/V, serum albumin, frequency of hospitalizations, frequency of infection, medications, Hgb, the dose of erythropoietin, ferritin and use of iron preparations were collected in all patients from January 2020 to June 2020. Time since HIV diagnosis, counts of CD4+ T cells, HIV RNA, and antiretroviral therapy for HIV infection were collected in HIV-infected patients. Multiple data in different time points of one parameter in the same patient were expressed as mean. This study was approved by the ethics committee of Sichuan Provincial People's Hospital (No. 2017-124). All participants provided written informed consent. All procedures in this study were in accordance with the Declaration of Helsinki. 


\section{Statistical analysis}

The normality of continuous data was evaluated using the Shapiro-Wilk test. Normally distributed data were expressed as means \pm standard deviations (SDs) and assessed using the t-test, whereas non-normally distributed data were expressed as median and interquartile range (IQR) and the Mann Whitney $U$ test was applied. The chi-square statistics or Fisher's exact test were used for categorical variables. Hgb, ferritin, dialysis vintage, hospitalizations, infections and serum albumin were compared using the Mann Whitney U test. Weekly erythropoietin dose, age and spKt/V were compared using the $\mathrm{t}$-test. Gender, medication and proportion of treatment with iron preparations were compared using chi-square statistics or Fisher's exact test. Statistical analyses were conducted in SPSS (version 26.0). A value of $p<0.05$ was considered significant.

\section{Results}

Baseline characteristics of enrolled patients

Thirty-four HIV-infected patients and thirty-five nonHIV-infected patients were included in the study with data collection from January 2020 to June 2020. The baseline characteristics are presented in Table 1. Gender, age, dialysis vintage, spKt/V, serum albumin, hospitalizations, infections and medications of HIV group are not statistically different from the control group except the proportion of treatment with $\alpha$-ketoacid. The different proportion in $\alpha$-ketoacid usage may be due to different health coverage policy in two dialysis centers. However, serum albumin of the two groups showed no statistically

Table 1 Baseline characteristics of enrolled patients

\begin{tabular}{lll}
\hline Group & Control $(\boldsymbol{n}=\mathbf{3 5})$ & HIV $(\boldsymbol{n}=\mathbf{3 4})$ \\
\hline Gender (male: female) & $29: 6$ & $29: 5$ \\
Age (year) & $44.69 \pm 8.88$ & $45.18 \pm 7.73$ \\
Dialysis vintage (month) & $25(17-37)$ & $26(13-36)$ \\
spKt/N & $1.34 \pm 0.23$ & $1.27 \pm 0.16$ \\
Serum albumin (g/L) & $42.10(40.35-43.40)$ & $41.95(38.88-43.55)$ \\
Hospitalizations (times/6 m) & $0(0-0)$ & $0(0-1)$ \\
Infections (times/6 m) & $0(0-0)$ & $0(0-0)$ \\
Medications & & \\
Antihypertensive drugs (Y/N) & $33 / 2$ & $31 / 3$ \\
Phosphate binders (Y/N) & $34 / 1$ & $31 / 3$ \\
Active vitamin D or Cinacalcet & $33 / 2$ & $34 / 0$ \\
(Y/N) & & $2 / 32^{*}$ \\
a-Ketoacid (Y/N) & $13 / 22$ &
\end{tabular}

Dialysis vintage, serum albumin, hospitalizations and infections expressed as median IQR, Age and spKt/V expressed as means \pm SEM. Results of HIV group are not statistically different from control group except the proportion of treatment with a-ketoacid.

${ }^{*} p<0.05$ compared to control. difference indicating that this disparity had no impact on the nutritional status. The two groups were well matched.

\section{Clinical characteristics of HIV infected patients}

Thirty-four HIV-infected patients were enrolled in this study. The mean time since the HIV diagnosis was $49.62 \pm 28.86$ months. Except for two patients for personal reasons, antiretroviral drugs were administrated in the remaining 32 patients. Five HIV patients had no results of CD4 $+\mathrm{T}$ cell counts from January 2020 to June 2020. Of the remaining 29 HIV patients, 7 (24.1\%) patients had a CD4 $+\mathrm{T}$ cell count of fewer than 200 cells/ $\mathrm{mm}^{3}$, and $5(17.2 \%)$ patients had a CD4 $+\mathrm{T}$ cell count of more than 500 cells $/ \mathrm{mm}^{3}$. Twelve HIV patients had no results of HIV-RNA from January 2020 to June 2020. Of the remaining $22 \mathrm{HIV}$ patients, only 1 (4.5\%) patient had an HIV viral load above the lower detection limit. The possible reason was the short time of diagnosis and treatment for this patient (Time since HIV diagnosis: 4 months). The above data in HIV-HD group indicated relatively stable state of HIV infection in these patients.

\section{$\mathrm{Hgb}$ and dose of erythropoietin}

The Hgb and responses to erythropoietin in HIV-infected HD patients and HD patients are shown in Table 2. The Hgb of HIV-HD and HD groups were 105.70 (95.93$112.08) \mathrm{g} / \mathrm{L}$ and 112.00 (93.00-126.00) g/L respectively. Although there was a trend toward higher hgb levels in the control population, it did not reach statistical significance $(P=0.064) .4 / 34(11.76 \%)$ patients in the HIV-HD group had $\mathrm{Hgb}<90 \mathrm{~g} / \mathrm{L}$, compared with $2 / 35$ (5.71\%) in the HD group $(P=0.642)$. There was a statistically significant higher erythropoietin dosage used in the HIV population ( $222.55 \pm 115.47 \mathrm{U} / \mathrm{kg} /$ week) compared to the HIV-negative group $(161.86 \pm 110.31 \mathrm{U} / \mathrm{kg} /$ week $)$ $(P=0.029)$.

\section{Ferritin and treatment with iron preparations}

The proportion of treatment with iron preparations and ferritin in HIV-infected HD patients and control HD patients are presented in Table 3. 16/34 (47.06\%) HIV-HD

Table 2 Hemoglobin and dose of erythropoietin in HIV-infected patients on hemodialysis

\begin{tabular}{lll}
\hline Group & Control $(\boldsymbol{n}=\mathbf{3 5})$ & HIV $(\boldsymbol{n}=\mathbf{3 4})$ \\
\hline $\begin{array}{l}\text { Hemoglobin }(\mathrm{g} / \mathrm{L}) \\
\begin{array}{l}\text { Weekly erythropoietin } \\
\text { dose }(\mathrm{U} / \mathrm{kg})\end{array}\end{array}$ & $112.00(93.00-126.00)$ & $105.70(95.93-112.08)$ \\
\hline
\end{tabular}

Hemoglobin expressed as median (IQR); Weekly erythropoietin expressed as means \pm SEM

${ }^{*} p<0.05$ compared to control 
Table 3 Ferritin and treatment with iron preparations

\begin{tabular}{lll}
\hline Group & Control $(\boldsymbol{n}=\mathbf{3 5})$ & HIV $(\boldsymbol{n}=\mathbf{3 4})$ \\
\hline Ferritin (ng/ml) & $272.70(205.00-434.00)$ & $316.50(117.38-589.75)$ \\
$\begin{array}{l}\text { Proportion of treat- } \\
\text { ment with iron prepa- }\end{array}$ & $5 / 35$ & $16 / 34^{*}$ \\
rations & \\
\hline $\begin{array}{l}\text { Ferritin expressed as median (IQR) } \\
{ }^{*} p<0.05 \text { compared to control }\end{array}$ &
\end{tabular}

patients and 5/35 (14.29\%) HD patients were treated with iron preparations $(P=0.003)$. The details of iron administration showed in supplemental table. The ferritin levels were $316.50(117.38-589.75) \mathrm{ng} / \mathrm{ml}$ and 272.70 (205.00$434.00) \mathrm{ng} / \mathrm{ml}$ in HIV-HD and HD groups respectively $(P=0.653)$.

\section{Discussion}

For adult HD patients, KDIGO suggests that ESAs therapy is used to avoid having the Hgb concentration fall below $90 \mathrm{~g} / \mathrm{L}$ by starting erythropoietin therapy when the $\mathrm{Hb}$ is between $90-100 \mathrm{~g} / \mathrm{L}$ in 2012 [19]. Our study showed that $11.76 \%$ of patients in the HIV-HD group and $5.71 \%$ of patients in the HD group had $\mathrm{Hgb}<90 \mathrm{~g} / \mathrm{L}$, compared with $18.8 \%$ patients in China Dialysis Outcomes and Practice Patterns Study (DOPPS) [20]. The reason for the lower prevalence of $\mathrm{Hgb}<90 \mathrm{~g} / \mathrm{L}$ maybe include younger age, shorter dialysis vintage, higher percentage of males and higher dialysis frequency in enrolled patients in our study (Table 4) [20]. There was no significant difference in Hgb and ferritin between HIV-HD and HD patients in our study. However, higher ESAs dosage and higher rate of treatment with iron preparations were observed in HIV-HD patients compared with controlled HD patients. Patients in our study used oral and intravenous iron and various effectiveness of different iron dosage forms made it difficult to compared the iron dose of the two groups quantitatively. Therefore, we compared the rates of treatment with iron preparations in two groups only.

The reasons for anemia in HIV-HD patients are complex. Increased levels of inflammatory cytokines, defective erythropoiesis, opportunistic infections, antiretroviral drugs, other drugs administered to treat infection, and malignancies in HIV-positive patients could aggravate the severity of anemia [14, 15]. Among all the reasons, systemic inflammation suppresses $\mathrm{Hgb}$ response to ESAs [21]. Therefore, we suppose that inflammation caused by HIV infection may reduce the sensibility to ESAs and lead to an increase in the demand for ESAs in HIV-HD patients. Unfortunately, the patients in this study did not routinely detect $\mathrm{C}$-reactive protein and other inflammatory indicators, which made it impossible to assess the inflammatory state. More ESAs means more adverse effect including hypertension and thrombotic events, et al. [22]. Several studies have shown that severe ESA hyporesponsiveness is associated with poor survival and suggested that even higher ESA doses might contribute to poor patient outcomes [23].

There are limited therapies for anemia in HIV-HD patients. Classical treatment includes ESAs, iron therapy, and blood transfusions. Higher dosage of ESAs and higher proportion of iron use were observed in this study in HIV-HD patients which may be attributed to the poor ESA responsiveness caused by HIV infection and may furtherly lead to more side effects and poor outcomes. However, apparent inflammation did not appear to affect the Hgb response with roxadustat [24], a hypoxia-inducible factor (HIF) prolyl hydroxylase inhibitor. HIF prolyl hydroxylase inhibitor like roxadustat and vadadustat which has been used for CKD-related anemia in recent years are oral and being developed to stabilize HIF and thereby mimic a state of cellular hypoxia [24, 25]. HIF prolyl hydroxylase inhibitor might be a new choice for anemia in HIV-HD patients.

Table 4 Different baseline characteristics of this study and DOPPS

\begin{tabular}{|c|c|c|c|}
\hline Group & Control $(n=35)$ & HIV $(n=34)$ & $\begin{array}{l}\text { China subgroup } \\
\text { of DOPPS } \\
\text { ( } n=1427)\end{array}$ \\
\hline Gender (male\%) & 82.9 & 85.3 & 54.6 \\
\hline Age (year) & $44.69 \pm 8.88$ & $45.18 \pm 7.73$ & $58.7 \pm 3.5$ \\
\hline Dialysis vintage (month) & $25.0(17.0-37.0)$ & $26.0(13.0-36.0)$ & $40.8(18.0-75.6)$ \\
\hline \multicolumn{4}{|l|}{ Dialysis frequency } \\
\hline 3-times per week (\%) & 100 & 100 & 79.8 \\
\hline 2-times per week (\%) & 0 & 0 & 20.2 \\
\hline
\end{tabular}

DOPPS, Dialysis Outcomes and Practice Patterns Study. Dialysis vintage expressed as median IQR, Age expressed as means \pm SEM 


\section{Conclusion}

In HIV-HD patients, a higher erythropoietin dosage and a higher proportion of iron use were observed compared with HD patients, however, there were no significant differences in $\mathrm{Hgb}$ and ferritin between the two groups. We supposed that inflammation caused by HIV infection maybe the reason of ESA hyporesponsiveness in HIV-HD patients. Further studies are required to confirm this hypothesis.

\author{
Abbreviations \\ CKD: Chronic Kidney Disease; HD: Hemodialysis; Hgb: Hemoglobin; AIDS: \\ Acquired immunodeficiency syndrome; PLWH: People living with HIV; ART \\ : Antiretroviral therapy; NADs: Non-AIDS-defining diseases; ESRD: End- \\ stage renal disease; ESAs: Erythropoiesis-stimulating agents; SDs: Standard \\ deviations.
}

\section{Supplementary Information}

The online version contains supplementary material available at https://doi. org/10.1186/s12882-022-02693-y.

Additional file 1: Table. Administration ofiron in the enrolled patients.

\section{Acknowledgements}

None

\section{Authors' contributions}

(I) Conception and design: All authors; (II) Administrative support: Guisen Li, Daqing Hong and Yanan He; (III) Provision of study materials or patients: Lei Peng, Daqing Hong, Jiong Zhang and Yanan He; (IV) Collection and assembly of data: Lei Peng, Jiong Zhang, Daqing Hong and Yanan He; (V) Data analysis and interpretation: Lei Peng and Daqing Hong; (VI) Manuscript writing: All authors; (VII) Final approval of manuscript: All authors.

\section{Funding}

This study was supported by grants from the Department of Science and Technology of Sichuan Province (www.scst.gov.cn, 2021YJ0144) and the Health Commission of Sichuan Province (http://wsjkw.sc.gov.cn/, 18PJ364). The funders played no role in the study design, data collection or analysis or manuscript preparation.

\section{Availability of data and materials}

Additional data and materials are available in REDCap.samsph.com:16,866 on reasonable request.

\section{Declarations}

\section{Ethics approval and consent to participate}

The study was approved by the ethics committee of Sichuan Provincial People's Hospital. All participants provided written informed consent prior to data collection. All procedures performed in this study involving human participants were in accordance with the Declaration of Helsinki (as revised in 2013).

\section{Consent for publication \\ Not applicable.}

\section{Competing interests}

No potential conflict of interest was reported by the authors.

\section{Author details}

'Department of Nephrology, Sichuan Provincial People's Hospital, University of Electronic Science and Technology of China, Chengdu 611731, China.
${ }^{2}$ School of Automation Engineering, University of Electronic Science and Technology of China, Chengdu 611731, China. ${ }^{3}$ Public Health Clinical Center of Chengdu, Chengdu, China.

Received: 8 November 2021 Accepted: 31 January 2022

Published online: 08 February 2022

\section{References}

1. collaborators GH. Global, regional, and national incidence, prevalence, and mortality of HIV, 1980-2017, and forecasts to 2030, for 195 countries and territories: a systematic analysis for the Global Burden of Diseases, Injuries, and Risk Factors Study 2017. The lancet HIV. 2019 Dec;6(12):e831e59. PubMed PMID: 31439534. Pubmed Central PMCID: 6934077.

2. Smith CJ, Ryom L, Weber R, Morlat P, Pradier C, Reiss P, et al. Trends in underlying causes of death in people with HIV from 1999 to 2011 (D:A:D): a multicohort collaboration. Lancet. 2014;384(9939):241-8 PubMed PMID: 25042234.

3. Smit M, Perez-Guzman PN, Mutai KK, Cassidy R, Kibachio J, Kilonzo N, et al. Mapping the Current and Future Noncommunicable Disease Burden in Kenya by Human Immunodeficiency Virus Status: A Modeling Study. Clin Infect Dis. 2020;71(8):1864-73 PubMed PMID: 31734688.

4. Liu J, Hou Y, Sun L, Wang L, He Y, Zhou Y, et al. High population-attributable fractions of traditional risk factors for non-AIDS-defining diseases among people living with HIV in China: a cohort study. Emerging microbes \& infections. 2021;10(1):416-23 PubMed PMID: 33620297.

5. Naicker S. HIV/AIDS and chronic kidney disease. Clinical nephrology. 2020;93(1):87-93.

6. Wearne N, Davidson B, Blockman M, Swart A, Jones ES. HIV, drugs and the kidney. Drugs in context. 2020;9:2019-11-1. PubMed PMID: 32256631 Pubmed Central PMCID: PMC7104683. Epub 2020/04/08. eng.

7. Swanepoel CR, Atta MG, D'Agati VD, Estrella MM, Fogo AB, Naicker S, et al. Kidney disease in the setting of HIV infection: conclusions from a Kidney Disease: Improving Global Outcomes (KDIGO) Controversies Conference. Kidney international. 2018;93(3):545-59 PubMed PMID: 29398134. Pubmed Central PMCID: 5983378.

8. Heron JE, Bagnis Cl, Gracey DM. Contemporary issues and new challenges in chronic kidney disease amongst people living with HIV. AIDS Res Ther. 2020;17(1):11 PubMed PMID: 32178687. Pubmed Central PMCID: PMC7075008. Epub 2020/03/18. eng.

9. Halle MP, Edjomo AM, Fouda H, Djantio H, Essomba N, Ashuntantang GE. Survival of HIV infected patients on maintenance hemodialysis in Cameroon: a comparative study. BMC Nephrol. 2018;19(1):166 PubMed PMID: 29976156. Pubmed Central PMCID: PMC6034298. Epub 2018/07/07. eng.

10. Fabian J, Maher HA, Clark C, Naicker S, Becker P, Venter WD. Morbidity and mortality of black HIV-positive patients with end-stage kidney disease receiving chronic haemodialysis in South Africa. S Afr Med J. 2015;105(2):110-4 PubMed PMID: 26242528.

11. Grabovac I, Veronese N, Stefanac S, Haider S, Jackson SE, Koyanagi A, et al. Human Immunodeficiency Virus Infection and Diverse Physical Health Outcomes: An Umbrella Review of Meta-analyses of Observational Studies. Clin Infect Dis. 2020;70(9):1809-15 PubMed PMID: 31401650. Pubmed Central PMCID: 7156772.

12. Lee KH, Ho Y, Tarng DC. Iron Therapy in Chronic Kidney Disease: Days of Future Past. International journal of molecular sciences. 2021;22(3). PubMed PMID: 33498292. Pubmed Central PMCID: 7863960.

13. Hanna RM, Streja E, Kalantar-Zadeh K. Burden of Anemia in Chronic Kidney Disease: Beyond Erythropoietin. Adv Ther. 2021;38(1):52-75 PubMed PMID: 33123967. Pubmed Central PMCID: 7854472.

14. Tsukamoto T. Hematopoietic Stem/Progenitor Cells and the Pathogenesis of HIV/AIDS. Frontiers in cellular and infection microbiology. 2020;10:60 PubMed PMID: 32154191. Pubmed Central PMCID: 7047323.

15. Mandayam S, Ahuja TS. Dialyzing a patient with human immunodeficiency virus infection: what a nephrologist needs to know. American journal of nephrology. 2004;24(5):511-21 PubMed PMID: 15452404. Epub 2004/09/29. eng.

16. Shrivastava D, Rao TK, Sinert R, Khurana E, Lundin AP, Friedman EA. The efficacy of erythropoietin in human immunodeficiency virus-infected end-stage renal disease patients treated by maintenance hemodialysis. American journal of kidney diseases : the official journal of the National 
Kidney Foundation. 1995;25(6):904-9 PubMed PMID: 7771487. Epub 1995/06/01. eng.

17. Balsam L, Attia AM, Sharma NP. Achieving KDOQI Guidelines for Hematocrit in HIV-Infected Hemodialysis Patients. Ren Fail. 2009;31 (3):189-91 PubMed PMID: 19288322.

18. LuX, Sun H, Li H, Xia W, Wu H, Chen D, et al. Validation of the BD FACSPresto system for the measurement of CD4 T-lymphocytes and hemoglobin concentration in HIV-negative and HIV-positive subjects. Sci Rep. 2020;10(1):19605 PubMed PMID: 33177659. Pubmed Central PMCID: 7658244.

19. Group KDIGOKAW. KDIGO Clinical Practice Guideline for Anemia in Chronic Kidney Disease. Kidney International Supplements. 2012 AUGUST 2 2012;2(4):279-335.

20. Zhao X, Niu Q, Gan L, Hou FF, Liang X, Ni Z, et al. Baseline data report of the China Dialysis Outcomes and Practice Patterns Study (DOPPS). Sci Rep. 2021;11(1):873 PubMed PMID: 33441625. Pubmed Central PMCID: 7806992.

21. Karaboyas A, Morgenstern H, Fleischer NL, Vanholder RC, Dhalwani NN, Schaeffner E, et al. Inflammation and Erythropoiesis-Stimulating Agent Response in Hemodialysis Patients: A Self-matched Longitudinal Study of Anemia Management in the Dialysis Outcomes and Practice Patterns Study (DOPPS). Kidney medicine. 2020;2(3):286-96 PubMed PMID: 32734248. Pubmed Central PMCID: 7380435

22. Koulouridis I, Alfayez M, Trikalinos TA, Balk EM, Jaber BL. Dose of erythropoiesis-stimulating agents and adverse outcomes in CKD: a metaregression analysis. Am J Kidney Dis. 2013;61(1):44-56 PubMed PMID: 22921639. Pubmed Central PMCID: 3525813.

23. Nakanishi T, Kuragano T, Nanami M, Nagasawa Y, Hasuike Y. Misdistribution of iron and oxidative stress in chronic kidney disease. Free Radic Biol Med. 2019;133:248-53 PubMed PMID: 29958932.

24. Chen N, Hao C, Liu BC, Lin H, Wang C, Xing C, et al. Roxadustat Treatment for Anemia in Patients Undergoing Long-Term Dialysis. N Engl J Med. 2019:381(11):1011-22 PubMed PMID: 31340116.

25. Eckardt KU, Agarwal R, Aswad A, Awad A, Block GA, Bacci MR, et al. Safety and Efficacy of Vadadustat for Anemia in Patients Undergoing Dialysis. N Engl J Med. 2021;384(17):1601-12 PubMed PMID: 33913638.

\section{Publisher's Note}

Springer Nature remains neutral with regard to jurisdictional claims in published maps and institutional affiliations.

Ready to submit your research? Choose BMC and benefit from:

- fast, convenient online submission

- thorough peer review by experienced researchers in your field

- rapid publication on acceptance

- support for research data, including large and complex data types

- gold Open Access which fosters wider collaboration and increased citations

- maximum visibility for your research: over $100 \mathrm{M}$ website views per year

At BMC, research is always in progress.

Learn more biomedcentral.com/submissions 